\title{
The Effects of Body Mass Composition and Cushion Type on Seat-Interface Pressure in Spinal Cord Injured Patients
}

\author{
Kang Hee Cho, MD, Jaewon Beom, MD, Jee Hyun Yuk, PhD, Seung-Chan Ahn, MD
}

Department of Rehabilitation Medicine, Chungnam National University School of Medicine, Daejeon, Korea

\begin{abstract}
Objective To investigate the effects of body mass composition and cushion type on seat-interface pressure in spinal cord injured (SCI) patients and healthy subjects.

Methods Twenty SCI patients and control subjects were included and their body mass composition measured. Seat-interface pressure was measured with participants in an upright sitting posture on a wheelchair with three kinds of seat cushion and without a seat cushion. We also measured the pressure with each participant in three kinds of sitting postures on each air-filled cushion. We used repeated measure ANOVA, the Mann-Whitney test, and Spearman correlation coefficient for statistical analysis.

Results The total skeletal muscle mass and body water in the lower extremities were significantly higher in the control group, whilst body fat was significantly higher in the SCI group. However, the seat-interface pressure and body mass composition were not significantly correlated in both groups. Each of the three types of seat cushion resulted in significant reduction in the seat-interface pressure. The SCI group had significantly higher seatinterface pressure than the control group regardless of cushion type or sitting posture. The three kinds of sitting posture did not result in a significant reduction of seat-interface pressure.

Conclusion We confirmed that the body mass composition does not have a direct effect on seat-interface pressure. However, a reduction of skeletal muscle mass and body water can influence the occurrence of pressure ulcers. Furthermore, in order to minimize seat-interface pressure, it is necessary to apply a method fitted to each individual rather than a uniform method.
\end{abstract}

Keywords Spinal cord injuries, Body mass index, Pressure ulcer, Pressure

Received April 22, 2015; Accepted July 17, 2015

Corresponding author: Seung-Chan Ahn

Department of Rehabilitation Medicine, Daejeon Regional Rehabilitation Center, Chungnam National University, 266 Munhwa-ro, Jung-gu, Daejeon 35015 , Korea

Tel: +82-42-338-2460, Fax: +82-42-338-2461, E-mail: asc88@cnuh.co.kr

(c) This is an open-access article distributed under the terms of the Creative Commons Attribution Non-Commercial License (http://creativecommons.org/ licenses/by-nc/4.0) which permits unrestricted noncommercial use, distribution, and reproduction in any medium, provided the original work is properly cited. Copyright () 2015 by Korean Academy of Rehabilitation Medicine 


\section{INTRODUCTION}

Pressure ulcers are an acquired complication common in patients with lack of mobility and poor hygiene. They occur due to pressure concentrated on bony prominences, which interrupts blood circulation, and is often induced as a consequence of various clinical diseases, such as stroke or spinal cord injury (SCI), as well as postoperative long-time immobility [1]. Pressure ulcers are also a cause of longer hospital stays, increased medical costs, and delays in active rehabilitation of patients. Factors associated with the occurrence of pressure ulcers are external pressure, shear stress, skin temperature, nutrition, humidity, or blood circulation in the local area. Among these, pressure is considered to be the important mechanical factor [2]. The total cost per patient for care is approximately $\$ 9,600$ in other countries, incurring severe economic losses and prolonged healing time, and leading to possible cardiovascular dysfunction, sepsis, and even death. It is therefore crucial to focus on the prevention of pressure ulcers rather than their treatment $[3,4]$.

The most promising interventions for the effective prevention of pressure ulcers are the use of appropriate seatcushion materials, repositioning of the patient, improvement in patient nutrition, and skin moisturization [5]. One study found that $36 \%$ to $50 \%$ of pressure ulcers in the elderly are ascribed to sitting in a wheelchair, indicating that the importance of reducing seat-interface pressure for patients sitting in a wheelchair for a long time [6]. Factors affecting seat-interface pressure are body composition properties such as the patient's weight, body mass index (BMI), amount of skeletal muscle, and body water. Several studies have reported the correlation between these factors and seat-interface pressure [7-9]. However, there is no consensus on the correlation between body composition and seat-interface pressure, and few studies have estimated seat-interface pressure by BMI among patients with SCI.

Several studies have been performed to evaluate the effectiveness of various cushions or mattresses in reducing seat-interface pressures. These studies focused on the prevention of pressure ulcers among patients with SCI who cannot easily change postures. One study found that the use of a cushion which reduces the seat-interface pressure, with maximum stress force inferior to the ischial tuberosity, provided stability and comfort [10]. Cur- rently, there are many cushions commercially available and they take many forms such as water, foam, gel, air, or viscoelastic cushions. Previous studies reported on the changes in the distribution of pressure according to different sitting postures, duration of sitting time, or cushion type. Several other studies have compared and determined higher seating pressures in persons with SCI than in able-bodied subjects, but so far no pressure ulcers prevention protocol has been developed that is suitable for each patient, and limited research has been conducted on treatment effects on seat-interface pressure based on air cushion types with comparison of SCI patients and a healthy group.

In this study, we examined the correlation between seat-interface pressure and the body composition factors of body weight, BMI, skeletal muscle, and body water. We then investigated the effects of air cushion type and various sitting postures on seat-interface pressure changes, and compared the results between SCI patients and a healthy group.

\section{MATERIALS AND METHODS}

\section{Subjects}

Twenty patients with SCI and another 20 healthy adults without any musculoskeletal or nervous system injuries were enrolled in this study. The inclusion criteria were patients with cervical or thoracic SCI (both complete and incomplete), absence of pressure ulcers in the past few months, absence of history of surgical procedures on any part of the hip joint or femur, and a greater than $90^{\circ}$ range of hip flexion motion.

\section{Methods}

To compare body composition between the SCI and control groups, total and segmental skeletal muscle mass, body weight, BMI, body fat and segmental body water were measured using Biospace InBody S10 (Biospace, Seoul, Korea).

We applied the CONFORMat System (Tekscan, Boston, MA, USA) to a recline wheelchair for measuring the seatinterface pressure with participants in a sitting position. Pressure was measured at each sitting position for 10 seconds and averaged by the sensor with 1,024 sensing elements distributed over 32 rows and 32 columns. We installed a region of interest (ROI) on the ischial tuberos- 
ity and pulled out the dot that recorded the peak pressure (Fig. 1).

Seat-interface pressure was measured under the following four conditions: no cushion, a low-cost air cushion (commercially available at about $\$ 8$ ), a 5-cm antidecubitus air cushion (ROHO Quadtro Select cushion; The ROHO Group, Belleville, IL, USA), and a 10-cm antidecubitus air cushion (Fig. 2). The ROHO cushion was prepared by over-inflation of all cells, followed by release of the air until the examiner's hand on the patient's bony prominence touches the base of the cushion.

In addition, with and without an air cushion, the seatinterface pressure was measured in the three sitting positions: upright, $20^{\circ}$ posterior leaning posture, and $20^{\circ}$ trunk forward flexion posture. For the upright sitting position, the study participant put his or her pelvis to the end of the wheelchair floor, positioned the body and pelvis in the center of the wheelchair with their head in the same vertical line along the body looking straight ahead, put their arms on the lap board and their feet on the floor without a foot rest, and held their hip, knee, and ankle joints at $90^{\circ}$. If their legs were too short to reach the floor, we padded the board below the feet for positioning as above. For the $20^{\circ}$ posterior leaning posture, each participant sat on the recline wheelchair tilted backward by $20^{\circ}$. Similarly, for the $20^{\circ}$ trunk forward flexion posture, a participant placed both arms on the lap board and tilted the trunk forward, keeping every other posture similar to the upright sitting position (Fig. 3). One rehabilitation physiatrist and one physical therapist observed the participant's posture and measured the seat-interface pressure. In addition, data collected whilst patients made movements caused by actions such as sneezing or coughing were excluded since they could have interfered with correct data collection. Every participant wore the same cotton patient pants with a wide side.

All statistical analysis was conducted using SPSS ver. 19.0 for Windows (IBM SPSS, Armonk, NY, USA). p-values $<0.05$ from repeated measure ANOVA, the Mann-Whitney test, and Spearman correlation were considered statisti-
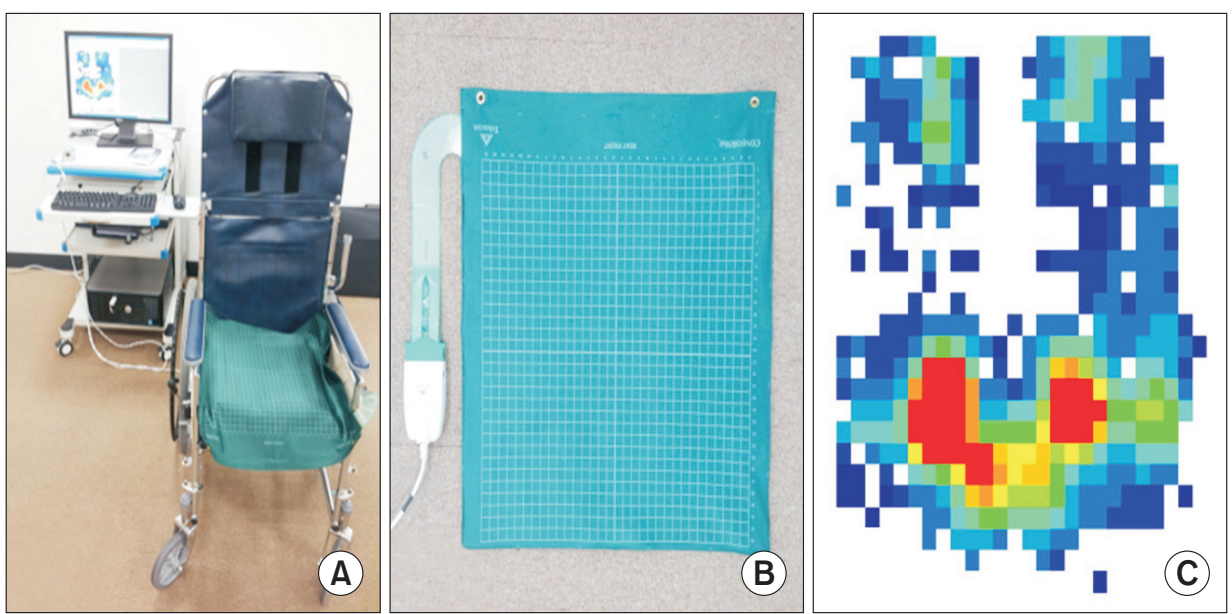

(A)

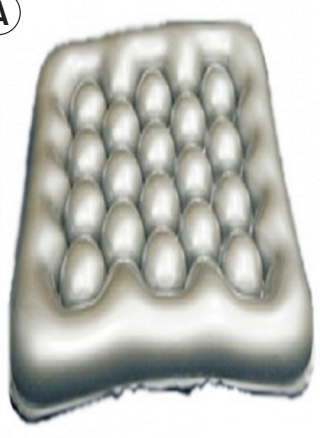

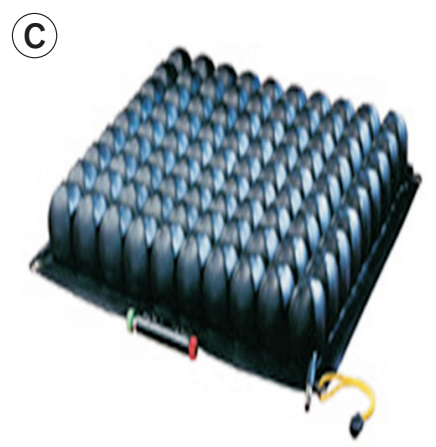

Fig. 1. Measurement of seat interface pressure. (A) Pressure mapping technology showing a computer with pressure mapping software, flexible sensor pad and electronics unit. (B) CONFORMat pressure sensor. (C) An example of pressure distribution on the buttocks.
Fig. 2. Cushions analyzed in the present study. (A) Low-priced airfilled cushion. (B) $5 \mathrm{~cm}$ air-filled cushion (ROHO). (C) $10 \mathrm{~cm}$ airfilled cushion (ROHO). 

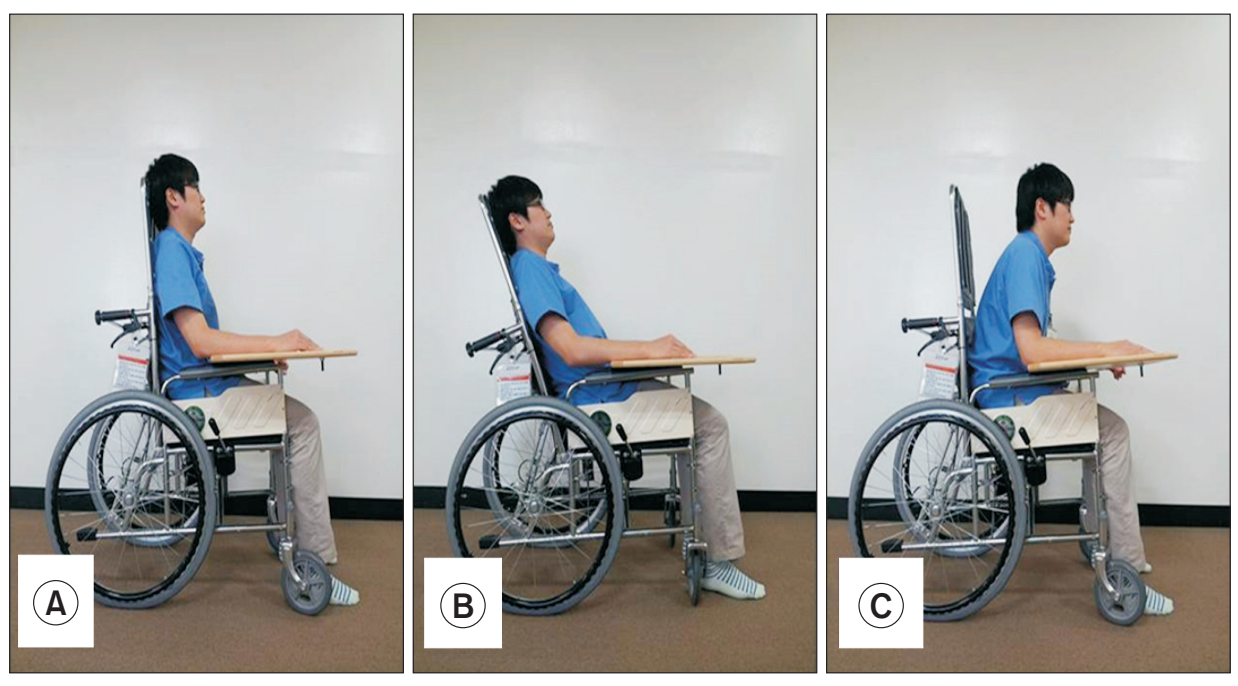

Fig. 3. (A) Upright sitting posture, (B) $20^{\circ}$ posterior leaning posture, (C) $20^{\circ}$ trunk forward flexion posture. cally significant.

\section{RESULTS}

The mean ages of the study subjects were $53.6 \pm 17.9$ and $27.5 \pm 2.54$ years in the SCI group and the control group, respectively. This age difference was statistically significant, but differences in height and weight were not statistically significant (Table 1). The mean duration of SCI was $129.06 \pm 111.85$ days. Three patients were classified as having complete paralysis and the other 17 patients were classified as having incomplete paralysis based on the International Standards for Neurological Classification of Spinal Cord Injury (ISNCSCI). The level of SCI varied over the range from $\mathrm{C} 4$ to $\mathrm{T} 12$ (13 tetraplegia, 7 paraplegia). There were no significant differences in terms of body composition and seat-interface pressure according to SCI level (Table 2).

The correlation between body composition and seatinterface pressure

The total skeletal muscle mass and muscle mass of the lower extremities were $29.21 \pm 5.27 \mathrm{~kg}$ and $16.02 \pm 3.61 \mathrm{~kg}$ in the control group, respectively, and were statistically significantly higher compared to that in the group with SCI $(24.31 \pm 6.16 \mathrm{~kg}, 13.37 \pm 3.73 \mathrm{~kg})$, but the skeletal muscle mass of the trunk was similar in both groups. Body fat was significantly higher in the SCI group, but body water of the lower extremities was higher in the control group (Table 1). Body weight, BMI, and body water of the trunk were not statistically different.
Table 1. General characteristics and body mass composition in SCI and control groups

\begin{tabular}{|c|c|c|}
\hline Characteristic & SCI group & Control group \\
\hline Sex (male:female) & $13: 7$ & $13: 7$ \\
\hline Age $(y r)^{*}$ & $53.6 \pm 17.95$ & $27.5 \pm 2.54$ \\
\hline Height (cm) & $164.15 \pm 9.64$ & $169.66 \pm 6.85$ \\
\hline Body weight $(\mathrm{kg})$ & $64.72 \pm 9.06$ & $65.35 \pm 11.83$ \\
\hline BMI $\left(\mathrm{kg} / \mathrm{m}^{2}\right)$ & $24.30 \pm 3.38$ & $22.56 \pm 3.04$ \\
\hline Body fat (kg)* & $19.40 \pm 7.50$ & $15.01 \pm 6.09$ \\
\hline \multicolumn{3}{|c|}{ Skeletal muscle mass (kg) } \\
\hline Total* & $24.32 \pm 6.16$ & $29.21 \pm 5.28$ \\
\hline Trunk & $20.78 \pm 4.31$ & $21.69 \pm 3.27$ \\
\hline Lower extremity* & $13.37 \pm 3.73$ & $16.02 \pm 3.61$ \\
\hline \multicolumn{3}{|c|}{ Segmental body water (L) } \\
\hline Trunk & $16.26 \pm 3.34$ & $17.49 \pm 2.40$ \\
\hline Lower extremity* & $10.48 \pm 2.89$ & $12.88 \pm 2.33$ \\
\hline
\end{tabular}

Values are presented as mean \pm standard deviation. SCI, spinal cord injury; BMI, body mass index. ${ }^{*} \mathrm{p}<0.05$, indicates a significant difference between spinal cord injury and control group.

All measured variables of body mass composition did not show significant correlations with seat-interface pressure in both groups (Table 3 ).

Change in seat-interface pressure according to wheelchair cushion type

The three kinds of seat cushion used in our study resulted in significant reduction in the seat-interface pressure over no cushion (Fig. 4, Table 4). Patients who used a 
low-cost air cushion, a 5-cm anti-decubitus air cushion, or a $10-\mathrm{cm}$ anti-decubitus air cushion had mean seatinterface pressures of $109.88 \pm 27.34 \mathrm{mmHg}, 109.84 \pm 45.14$ $\mathrm{mmHg}$, and $102.41 \pm 29.56 \mathrm{mmHg}$, respectively. The average difference in the seat-interface pressure levels among the three air cushions was less than $7 \mathrm{mmHg}$, which is not statistically significant. However, according to pressure mapping, a 5-cm anti-decubitus air cushion or a 10$\mathrm{cm}$ anti-decubitus air cushion induced greater pressure distribution than the low-cost air cushion.

Except for the low-cost air cushion with the upright posture and $10 \mathrm{~cm}$ anti-decubitus air cushion with the $20^{\circ}$ posterior leaning posture, the SCI group had significantly higher seat-interface pressure than the control group regardless of cushion type or sitting posture.

Change in seat-interface pressure according to sitting posture

We measured the seat-interface pressure for the three positions of upright, $20^{\circ}$ posterior leaning posture, and $20^{\circ}$ trunk forward flexion posture, and with three different air cushions and without an air cushion. There were

Table 2. The body mass composition and seat-interface pressure based on the ISNCSCI

\begin{tabular}{|lccc}
\hline & Tetraplegia & Paraplegia & p-value \\
\hline Body weight $(\mathrm{kg})$ & $63.81 \pm 9.63$ & $66.41 \pm 8.33$ & 0.975 \\
\hline BMI $\left(\mathrm{kg} / \mathrm{m}^{2}\right)$ & $24.01 \pm 3.58$ & $24.83 \pm 3.15$ & 0.611 \\
\hline Body fat $(\mathrm{kg})$ & $17.62 \pm 6.90$ & $22.80 \pm 7.97$ & 0.575 \\
\hline Skeletal muscle mass $(\mathrm{kg})$ & & & \\
\hline Total & $24.85 \pm 5.54$ & $23.31 \pm 7.55$ & 0.743 \\
\hline Trunk & $20.92 \pm 3.78$ & $20.51 \pm 5.49$ & 0.355 \\
\hline Lower extremity & $13.38 \pm 3.66$ & $13.36 \pm 4.15$ & 0.964 \\
\hline Segmental body water (L) & & & \\
\hline Trunk & $16.35 \pm 2.93$ & $16.07 \pm 4.25$ & 0.350 \\
\hline Lower extremity & $10.47 \pm 2.85$ & $10.49 \pm 3.18$ & 0.992 \\
\hline Seat-interface pressure (mmHg) & & & \\
\hline No cushion & $214.12 \pm 48.95$ & $227.67 \pm 97.19$ & 0.095 \\
\hline Low priced air cushion & $102.60 \pm 19.08$ & $123.29 \pm 73.49$ & 0.443 \\
\hline 5 cm ROHO cushion & $99.97 \pm 24.50$ & $106.93 \pm 39.09$ & 0.055 \\
\hline 10 cm ROHO cushion & $63.81 \pm 9.63$ & $66.41 \pm 8.33$ & 0.610 \\
\hline
\end{tabular}

Values are presented as mean \pm standard deviation.

ISNCSCI, International Standards for Neurological Classification of Spinal Cord Injury; BMI, body mass index.

Table 3. Correlation coefficients and p-value between body mass composition and seat-interface pressure

\begin{tabular}{|lcc}
\hline & SCI group & Control group \\
\hline Body weight $(\mathrm{kg})$ & $0.136(\mathrm{p}=0.567)$ & $-0.168(\mathrm{p}=0.479)$ \\
\hline BMI $\left(\mathrm{kg} / \mathrm{m}^{2}\right)$ & $-0.207(\mathrm{p}=0.382)$ & $-0.052(\mathrm{p}=0.826)$ \\
\hline Body fat $(\mathrm{kg})$ & $-0.108(\mathrm{p}=0.652)$ & $-0.204(\mathrm{p}=0.389)$ \\
\hline Skeletal muscle mass $(\mathrm{kg})$ & & \\
\hline Total & $0.152(\mathrm{p}=0.523)$ & $-0.135(\mathrm{p}=0.569)$ \\
\hline Trunk & $0.218(\mathrm{p}=0.355)$ & $-0.350(\mathrm{p}=0.131)$ \\
\hline Lower extremity & $0.144(\mathrm{p}=0.544)$ & $-0.274(\mathrm{p}=0.243)$ \\
\hline Segmental body water $(\mathrm{L})$ & & $-0.089(\mathrm{p}=0.708)$ \\
\hline Trunk & $0.237(\mathrm{p}=0.315)$ & $-0.180(\mathrm{p}=0.449)$ \\
\hline Lower extremity & $0.149(\mathrm{p}=0.531)$ & \\
\hline
\end{tabular}

SCI, spinal cord injury; BMI, body mass index. 
no statistically significant pressure differences among the different sitting postures (Fig. 5).

\section{DISCUSSION}

In this study, we found that all measured variables in body mass composition did not show significant correlations with seat-interface pressure in both groups. However, the total skeletal muscle mass was $24.31 \pm 6.16 \mathrm{~kg}$ in the SCI group, significantly lower than $29.21 \pm 5.27 \mathrm{~kg}$ measured in the control group. Body fat was higher in the SCI group $(19.40 \pm 7.50 \mathrm{~kg})$ when compared to that in the control group (15.01 $\pm 6.08 \mathrm{~kg})$. Gefen [11] reported that the chance of pressure ulcers is increased due to anatom-

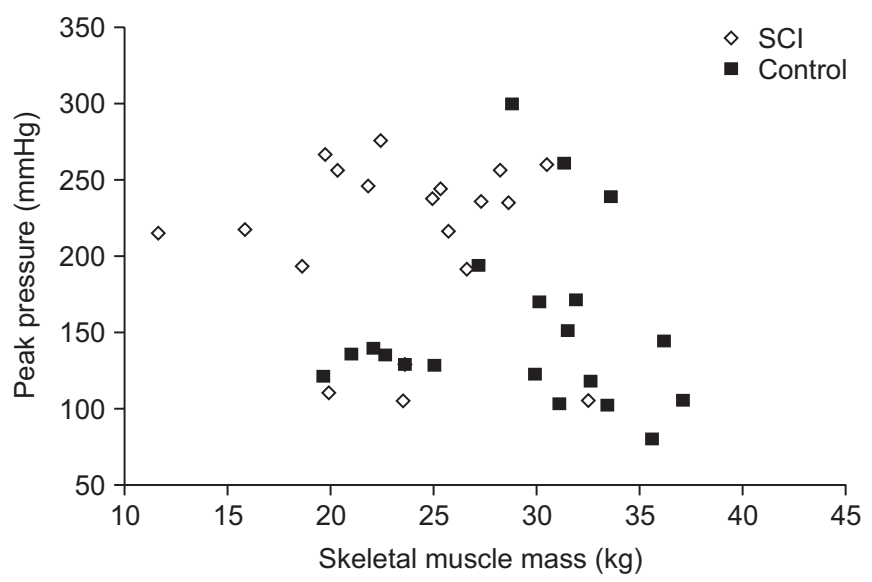

Fig. 4. Correlation between seat-interface peak pressure and skeletal muscle mass in spinal cord injury (SCI) and control groups. ical and functional changes from SCI following the loss of sense and mobility. In particular, these changes typically include weight and fat mass gain, skeletal muscle mass atrophy, bone loss and bone shape accommodation at the pelvis, vascular perfusion changes, and microstructural changes in skin and muscle.

Researchers have previously reported that there is a significant positive correlation between seat-interface pressure and BMI, with obesity contributing to elevated tissue loads and accordingly and increase in the possibility of deep tissue injury in patients $[12,13]$. In addition, Sopher



Fig. 5. Effect of seat cushion on seat-interface peak pressure in spinal cord injury (SCI) and control groups. ${ }^{\text {a) }}$ indicates a significant difference between SCI and control. ${ }^{b)}$ indicates a significant difference depending on application of wheelchair cushion.

Table 4. Mean of seat-interface peak pressure ( $\mathrm{mmHg}$ ) in spinal cord injury (SCI) and control groups

\begin{tabular}{|cccc|}
\hline & Upright & $\mathbf{2 0}^{\circ}$ Post leaning posture & $\mathbf{2 0}^{\circ}$ Forward flexion posture \\
\hline SCI group & & & \\
\hline No cushion & $218.86 \pm 67.38^{\mathrm{a})}$ & $231.67 \pm 44.69^{\mathrm{a})}$ & $218.02 \pm 51.81^{\mathrm{a})}$ \\
\hline Low priced air cushion & $109.88 \pm 27.34^{\mathrm{b})}$ & $\left.110.39 \pm 27.48^{\mathrm{a}, \mathrm{b}}\right)$ & $113.90 \pm 30.13^{\mathrm{a}, \mathrm{b})}$ \\
\hline 5 cm ROHO cushion & $109.84 \pm 45.14^{\mathrm{a}, \mathrm{b})}$ & $110.43 \pm 39.67^{\mathrm{a}, \mathrm{b}} \mathrm{b}$ & $112.85 \pm 40.39^{\mathrm{a}, \mathrm{b})}$ \\
\hline 10 cm ROHO cushion & $\left.102.41 \pm 29.56^{\mathrm{a}, \mathrm{b}}\right)$ & $98.96 \pm 26.88^{\mathrm{b})}$ & $97.50 \pm 20.53^{\mathrm{a}, \mathrm{b})}$ \\
\hline Control group & & & \\
\hline No cushion & $152.53 \pm 56.26^{\mathrm{a})}$ & $163.54 \pm 44.69^{\mathrm{a})}$ & $147.81 \pm 51.81^{\mathrm{a})}$ \\
\hline Low priced air cushion & $95.58 \pm 24.3^{\mathrm{b})}$ & $96.64 \pm 23.64^{\mathrm{a}, \mathrm{b})}$ & $97.90 \pm 24.75^{\mathrm{a}, \mathrm{b})}$ \\
\hline 5 cm ROHO cushion & $79.61 \pm 16.44^{\mathrm{a}, \mathrm{b})}$ & $80.47 \pm 17.08^{\mathrm{a}, \mathrm{b})}$ & $77.17 \pm 15.61^{\mathrm{a}, \mathrm{b})}$ \\
10 cm ROHO cushion & $80.80 \pm 14.15^{\mathrm{a}, \mathrm{b})}$ & $86.66 \pm 16.84^{\mathrm{b})}$ & $76.57 \pm 14.65^{\mathrm{a}, \mathrm{b})}$ \\
\hline
\end{tabular}

a)indicates a significant difference between spinal cord injury and control.

${ }^{b)}$ indicates a significant difference depending on application of wheelchair cushion. 
et al. [14] showed that internal muscle tissue loading inferior to the ischial tuberosity is increased in patients with an abnormally high or low BMI, and that deep tissue injury occurs as a consequence of this loading.

In contrast, some researchers have reported that seatinterface pressure levels did not correlate with body weight or BMI in SCI patients, and that seat-interface pressure levels appeared to be related to the shape of the buttocks, particularly the amount of soft tissue $[15,16]$. Similarly, we estimated that body mass composition would not have a direct effect on seat-interface pressure in the SCI group. However, changes in body mass composition induced by SCI such as low levels of skeletal muscle mass and body water have an indirect effect on the occurrence of pressure ulcers but the accumulation of body fat has no effect on the reduction of seat-interface pressure.

We found that the group with SCI had a higher seatinterface pressure than the control group, with or without the use of cushions. In particular, without wheelchair cushions, the seat-interface pressure was significantly different, measuring $218.86 \pm 67.38 \mathrm{mmHg}$ in the SCI group and $152.53 \pm 56.26 \mathrm{mmHg}$ in the control group, suggesting that there seems likely to be some damage to the tissue of buttocks due to high seat-interface pressure in the group with SCI.

Since pressure is defined as the force exerted per unit area, pressure increases as the contact area reduces. Gutierrez et al. [17] reported that the contact area in SCI subjects was less than half that in the control, whilst seatinterface pressure in SCI subjects was approximately double that in the control, despite relatively similar body weights. The seat-interface pressures are elevated by loading disproportions and are frequently accompanied by spine deformities. Furthermore, Linder-Ganz et al. [18] reported that a group with SCI had a delayed wound healing response along with anatomical changes between gluteal muscle thickness and the radius of curvature of the ischial tuberosity. Thorfinn et al. [19] reported that the hyperemic response in the buttock area is slightly lower in those with SCI, which is important for the occurrence of pressure ulcers.

When comparing the change in the seat-interface pressure due to the use of a wheelchair cushion, we found that there was a significant decrease in the seat-interface pressure when air cushions were applied as compared to the pressure without air cushions, while no significant differences in seat-interface pressure were found among the three cushions.

In the clinical study conducted by Yuen and Garrett [20], air cushions are more effective in reducing the pressure on the buttock as compared with gel or firm foam cushions. Burns and Betz [7] measured the pressure on the buttock among patients after applying high-profile air cushions, foam cushions, or dynamic cushions, and reported that when a dynamic cushion was used in a tiltin-space wheelchair, the pressure was lower than in the foam cushion but similar to that in an air cushion.

Gil-Agudo et al. [8] reported that when the pressure on the contact surface was measured using four types of wheelchair cushions (single compartment low-profile and high-profile air, dual-compartment air, and gel and firm foam) among 48 patients with SCI, the dualcompartment air cushion was the cushion with the most effective pressure distribution and largest contact area as compared with the other 3 cushions. In our study, there was no significant difference in the seat-interface pressure according to the different types of air cushions, which contrasts with the study by Gil-Agudo et al. [8]. These contrary results may be explained by the fact that, while Gil-Agudo et al. [8] compared single and dualcompartment air cushions, we used low-cost air cushions and cushions with Quadtro Select. We did not see a significant difference in seat-interface pressure between low-cost air cushions and high-cost air cushions. Therefore, even without high-cost cushions, if a patient uses a low-cost cushion properly, he or she can reduce the pressure on the buttocks effectively.

Furthermore, our study showed that changes in wheelchair sitting positions did not induce a significant change in the seat-interface pressure. However, according to a previous study conducted by Coggrave and Rose [9] on the changes in seat-interface pressure on the buttocks due to different sitting positions, bending side to side, leaning forward or tilting the back by more than $65^{\circ}$ is effective in decreasing the pressure. In the study of Hobson [21], when the seat-interface pressure was measured each time with forward flexion, backrest recline and full body tilt, the pressure was significantly reduced by $15 \%$ on forward flexion to $50^{\circ}$. In a study on the effect of wheelchair sitting positions on a patient with SCI, Kim et al. [22] reported that the seat-interface pressure of the buttocks showed the greatest reduction with a $90^{\circ}$ trunk forward flexion. Unlike the previous studies, we only measured 
the pressure with the participants in an upright position, in a $20^{\circ}$ posterior leaning posture, and $20^{\circ}$ trunk forward flexion posture, observing a limited effect on pressure reduction with a change of $20^{\circ}$. We chose these postures because the $20^{\circ}$ trunk forward flexion is needed cyclically during over-ground manual wheelchair propulsion in persons with SCI [23]. We may therefore expect to observe reductions in seat-interface pressure with bending or tiling beyond $20^{\circ}$. In practice, however, it is challenging for patients with SCI to change sitting positions by bending or tilting beyond $20^{\circ}$. Pressure reduction by posture change is transient, as it only occurs if the posture is kept. Thus, it is not a practical method for reducing pressure on the buttocks.

The strength of this study was that we used a control group of normal people and observed the correlation between seat-interface pressure and the body composition factors of weight, BMI, skeletal muscle mass, and body fat.

However, this study has a few limitations that need to be considered when designing further studies. First, we could not exclude variables related to age in the selection of the control group. To increase the reliability of the study, it equalization of the age of the control group should be considered. Second, we have included classification of the duration from onset or complete or incomplete paralysis in the statistical analysis of the SCI groups because due to a lack of individuals with SCI in our study sample. Finally, we only measured positions of a limited angle of $20^{\circ}$ for the change in seat-interface pressure according to the sitting postures.

As a result of this study, we confirmed that body mass composition does not have a direct effect on seat-interface pressure in the SCI group. However, a reduction of skeletal muscle mass and body water content induced by SCI has influence on the occurrence of pressure ulcers. Thus, we propose that strengthening exercises or electrical stimulation of the buttock area be used in order to increase the skeletal muscle mass in rehabilitation therapy for SCI.

Additionally, wheelchair cushions significantly reduced the seat-interface pressure of participants in a sitting position. Wheelchair cushions are therefore a useful method for preventing pressure ulcers in SCI. The type of wheelchair cushion and changes in sitting posture do not have a significant effect on seat-interface pressure.
We believe that when a wheelchair cushion is used to prevent pressure ulcers among patients with SCI, the patient's weight, BMI, and skeletal muscle mass need to be considered. In addition, prior to the start of use of a cushion, it is necessary to apply a method for minimization of the seat-interface pressure that is fitted to each individual rather than a uniform method.

\section{CONFLICT OF INTEREST}

No potential conflict of interest relevant to this article was reported.

\section{REFERENCES}

1. National Pressure Ulcer Advisory Panel. Pressure ulcers in America: prevalence, incidence, and implications for the future. An executive summary of the National Pressure Ulcer Advisory Panel monograph. Adv Skin Wound Care 2001;14:208-15.

2. Mawson AR, Biundo JJ Jr, Neville P, Linares HA, Winchester Y, Lopez A. Risk factors for early occurring pressure ulcers following spinal cord injury. Am J Phys Med Rehabil 1988;67:123-7.

3. Olin JW, Beusterien KM, Childs MB, Seavey C, McHugh L, Griffiths RI. Medical costs of treating venous stasis ulcers: evidence from a retrospective cohort study. Vasc Med 1999;4:1-7.

4. Gordon MD, Gottschlich MM, Helvig EI, Marvin JA, Richard RL. Review of evidenced-based practice for the prevention of pressure sores in burn patients. J Burn Care Rehabil 2004;25:388-410.

5. Reddy M, Gill SS, Rochon PA. Preventing pressure ulcers: a systematic review. JAMA 2006;296:974-84.

6. Aissaoui R, Kauffmann C, Dansereau J, de Guise JA. Analysis of pressure distribution at the body-seat interface in able-bodied and paraplegic subjects using a deformable active contour algorithm. Med Eng Phys 2001;23:359-67.

7. Burns SP, Betz KL. Seating pressures with conventional and dynamic wheelchair cushions in tetraplegia. Arch Phys Med Rehabil 1999;80:566-71.

8. Gil-Agudo A, De la Pena-Gonzalez A, Del Ama-Espinosa A, Perez-Rizo E, Diaz-Dominguez E, SanchezRamos A. Comparative study of pressure distribution at the user-cushion interface with different cushions 
in a population with spinal cord injury. Clin Biomech (Bristol, Avon) 2009;24:558-63.

9. Coggrave MJ, Rose LS. A specialist seating assessment clinic: changing pressure relief practice. Spinal Cord 2003;41:692-5.

10. Ragan R, Kernozek TW, Bidar M, Matheson JW. Seatinterface pressures on various thicknesses of foam wheelchair cushions: a finite modeling approach. Arch Phys Med Rehabil 2002;83:872-5.

11. Gefen A. Tissue changes in patients following spinal cord injury and implications for wheelchair cushions and tissue loading: a literature review. Ostomy Wound Manag 2014;60:34-45.

12. Stinson MD, Porter-Armstrong A, Eakin P. Seat-interface pressure: a pilot study of the relationship to gender, body mass index, and seating position. Arch Phys Med Rehabil 2003;84:405-9.

13. Elsner JJ, Gefen A. Is obesity a risk factor for deep tissue injury in patients with spinal cord injury? J Biomech 2008;41:3322-31.

14. Sopher R, Nixon J, Gorecki C, Gefen A. Exposure to internal muscle tissue loads under the ischial tuberosities during sitting is elevated at abnormally high or low body mass indices. J Biomech 2010;43:280-6.

15. Hamanami K, Tokuhiro A, Inoue H. Finding the optimal setting of inflated air pressure for a multi-cell air cushion for wheelchair patients with spinal cord injury. Acta Med Okayama 2004;58:37-44.

16. Brienza DM, Karg PE. Seat cushion optimization: a comparison of interface pressure and tissue stiffness characteristics for spinal cord injured and elderly patients. Arch Phys Med Rehabil 1998;79:388-94.

17. Gutierrez EM, Alm M, Hultling C, Saraste H. Measuring seating pressure, area, and asymmetry in persons with spinal cord injury. Eur Spine J 2004;13:374-9.

18. Linder-Ganz E, Shabshin N, Itzchak Y, Yizhar Z, SievNer I, Gefen A. Strains and stresses in sub-dermal tissues of the buttocks are greater in paraplegics than in healthy during sitting. J Biomech 2008;41:567-80.

19. Thorfinn J, Sjoberg F, Lidman D. Sitting pressure and perfusion of buttock skin in paraplegic and tetraplegic patients, and in healthy subjects: a comparative study. Scand J Plast Reconstr Surg Hand Surg 2002;36:27983.

20. Yuen HK, Garrett D. Comparison of three wheelchair cushions for effectiveness of pressure relief. Am J Occup Ther 2001;55:470-5.

21. Hobson DA. Comparative effects of posture on pressure and shear at the body-seat interface. J Rehabil Res Dev 1992;29:21-31.

22. Kim DA, Yi SH, Lee BS, Lim MH, Ryh BJ, Kim HC, et al. Impact of sitting time on seat-interface pressure of spinal cord injured patients. J Korean Acad Rehab Med 2009;33:614-8.

23. Julien MC, Morgan K, Stephens CL, Standeven J, Engsberg J. Trunk and neck kinematics during overground manual wheelchair propulsion in persons with tetraplegia. Disabil Rehabil Assist Technol 2014;9:213-8. 